\title{
Diversidad de plantas vasculares en bosques continuos y relictuales de Nothofagus antarctica (Nothofagaceae) en Patagonia austral
}

\author{
Diversity of vascular plants in continuous and relictual forests \\ of Nothofagus antarctica (Nothofagaceae) in southern Patagonia
}

Evangelina S. Vettese ${ }^{1}$, Ivonne A. Orellana Ibáñez ${ }^{2}$, María V. Lencinas ${ }^{3}$, Guillermo Martínez Pastur ${ }^{3}$ \& Pablo L. Peri ${ }^{4}$

\section{Resumen}

La historia de los bosques de Nothofagus antarctica (ñire, ñirre) está asociada a profundos disturbios geológicos y climáticos. A éstos se le suman los disturbios más recientes, que junto a los usos culturales de la tierra contribuyen a la fragmentación del hábitat. En el ecotono bosqueestepa, N. antarctica forma bosquetes insertos en una matriz de estepa llamados relictos. Éstos se encuentran separados de los bosques andinos que forman una masa boscosa continua. Con el fin de estudiar los patrones de diversidad de plantas vasculares comparativamente entre bosques relictuales (R) y sus bosques continuos aledaños (A), se relevaron cinco localidades de Santa Cruz. Éstas se ubican en un amplio gradiente latitudinal $\left(47^{\circ} 4^{\prime}-51^{\circ} 5^{\prime}\right.$ LS) y experimentan diferentes historias de uso. Los componentes alfa y beta de la diversidad fueron relacionados a otras variables ambientales mediante un análisis multivariado de redundancia (RDA). Un total de 152 especies fue registrado. La diversidad alfa se evaluó mediante el índice Shannon-Wiener $\left(H^{\prime}\right)$ y no hubo diferencias significativas $(p=0,585)$ entre los ambientes A y R. Sin embargo, el índice $H$ ' varió significativamente entre localidades ( $p<0,0001)$. Los mayores valores de $H^{\prime}$ se registraron en la localidad ubicada en el extremo latitudinal Norte, mientras que los menores valores de $H^{\prime}$ se registraron en la localidad ubicada en el extremo latitudinal Sur. El análisis de diversidad beta global $\left(\beta_{\text {sor }}\right)$ muestra más similitud entre los ambientes de las localidades ubicadas en los extremos Norte y Sur. Además, mientras que en la localidad más austral predomina el componente de diferenciación de especies por anidamiento $\left(\beta_{\text {nes }}\right)$, en las otras localidades predomina el componente de recambio de especies $\left(\beta_{\text {sim }}\right)$. El RDA demuestra que existe una estrecha relación entre las características ambientales (suelo y el clima) y la composición de especies. Asimismo, muestra que la temperatura media es el principal factor que relaciona a las localidades de los extremos Norte y Sur; localidades de baja similitud entre sí ( 1 y 5). Mientras que el mayor contenido de nutrientes en el suelo se relaciona a las localidades intermedias (2, 3 y 4). Se concluye que el gradiente latitudinal tiene fuertes influencias en la diversidad de la comunidad del sotobosque de N. antarctica. Además, la intensidad del uso histórico de los bosques estaría relacionada a una mayor disminución en la riqueza de plantas vasculares de relictos, con respecto a los bosques continuos aledaños. Esto último denota una mayor sensibilidad de relictos a los disturbios antrópicos y la necesidad de implementar medidas adecuadas de conservación de los ambientes naturales.

1 CIT - Santa Cruz - CONICET.

Av. Lisandro De La Torre 860 (9400) Río Gallegos,

Santa Cruz, Argentina.

$\searrow$ evangelinavettese@gmail.com

2 FCNyCS - UNPSJB. Ruta 259, km 16.4 Esquel, Chubut.

3 CADIC CONICET. Houssay 200 (9410) Ushuaia,

Tierra del Fuego, Argentina.

4 INTA EEA Santa Cruz - UNPA - CONICET. CC 332

(9400) Río Gallegos, Santa Cruz, Argentina. 


\section{Palabras clave:}

sotobosque, índices de biodiversidad, ecotono, gradientes ambientales, usos antrópicos.

\section{Abstract}

The history of Nothofagus antarctica forests in Santa Cruz is associated with significant geological and climatic disturbances. More recently, anthropic disturbances contributed to habitat fragmentation process. In the forest-steppe ecotone $N$. antarctica forms small forests inserted in a steppe matrix and separated from the Andean forests that are found towards the West forming continuous forest mass. Five localities of Santa Cruz were surveyed in order to study the patterns of diversity of vascular plants comparatively between relictual forests $(\mathrm{R})$ and their surrounding continuous forests (A). The localities are located in a wide latitudinal gradient $\left(47^{\circ} 4^{\prime}-51^{\circ} 5^{\prime} \mathrm{S}\right)$ and experience different histories of use. The alpha and beta components of the diversity were linked to other environmental variables through a multivariate redundancy analysis (RDA). A total of 152 species were registered. The alpha diversity was evaluated using the Shannon-Wiener Index $\left(H^{\prime}\right)$. There was no significant differences $(p=$ 0.585 ) between environments $\mathrm{A}$ and $\mathrm{R}$. However, when comparing the sites the differences were significant $(p<0.0001)$. The highest $H^{\prime}$ values were recorded in the northern site, while the lowest $H$ 'values occurred in southern site. The components analysis of global beta diversity $\left(\beta_{\text {sor }}\right)$ showed lower values in the northern and southern extreme locations. In addition, while in the most austral site the component of species differentiation by nesting $\left(\beta_{\text {nes }}\right)$ was more relevant, in the other evaluated sites the turnover component $\left(\beta_{\text {sim }}\right)$ was predominant. The RDA shows that there is a close relationship between environmental characteristics (soil and climate) and species composition. It also shows that mean temperature is the main factor that relates localities of low similarity to each other ( 1 and 5 ). While the higher nutrient content in the soil is related to the intermediate localities (2, 3 and 4). We concluded that the latitudinal gradient had strong influences on the diversity of the understory community of $N$. antarctica forests. Furthermore, the intensity of the historical use of the forests can be related to a greater decrease in the vascular plant richness in relicts compared to the surrounding continuous forests. This denotes a greater sensitivity of relicts to anthropogenic disturbances and the need of an adequate conservation action.

\section{Key words:}

understory, biodiversity indeces, ecotone, environmental gradients, anthropic uses.

\section{INTRODUCCIÓN}

Las comunidades que integran el bioma de los bosques templados de América del Sur constituyen una isla biogeográfica con baja diversidad biológica en relación con los restantes bosques continentales (Villagrán et al. 2005). Sin embargo, estos bosques tienen gran relevancia por la presencia de numerosos endemismos (Villagrán \& Hinojosa, 1997), géneros con pocas especies o géneros monotípicos exclusivos de esta región. La comunidad de plantas vasculares de los bosques del Sur de América del Sur se caracteriza por la presencia de elementos de diversos orígenes fitogeográficos, resultado de la integración de las sucesivas paleofloras (Schmithüsen, 1956; van der Hammen \& Cleef, 1983; Villagrán \& Hinojosa, 1997).

En la actualidad los bosques de Patagonia se encuentran sometidos principalmente a tres gradientes de variación climática; la temperatura disminuye conforme se incrementan la latitud y la altitud, en tanto la precipitación disminuye bruscamente en sentido oeste-este (Donoso, 1993; Blisniuk \& Stern, 2005). Asimismo, la viabilidad poblacional, la estructura de comunidades y el funcionamiento de estos ecosistemas pueden verse modificados cuando ocurren alteraciones del entorno abiótico por fragmentación (García, 2011; Pütz et al. 2011; Magnago et al. 2014). Este proceso implica la subdivisión de ambientes originalmente continuos en parches aislados por una matriz conformada por otro tipo de ambiente de mayor superficie (Wilcove \& May, 1986; Haila, 1995). En Patagonia han ocurrido procesos de fragmentación natural de los bosques a escalas de tiempo evolutivo, como por ejemplo la fragmentación producto de glaciaciones (Premoli et al. 2002; Villagrán \& Armesto, 2005). No obstante, durante el último siglo la fragmentación 
de los bosques ha estado asociada a procesos con un fuerte componente antrópico. Entre las diversas causas relacionadas con la disminución forestal se encuentran la apertura de nuevos caminos, las urbanizaciones no planificadas, el pastoreo intensivo, los incendios forestales y las extracciones forestales, entre otras (Carabelli et al. 2003; Suárez et al. 2004; Greslebin et al. 2015).

En el ecotono bosque-estepa de la provincia de Santa Cruz, Nothofagus antarctica (G. Forster) Oerst. (ñire o ñirre) se encuentra formando remanentes forestales insertos en una matriz de estepa, estos bosquetes constituyen las poblaciones en el límite oriental de su distribución natural (Peri \& Ormaechea, 2013). Se entiende por relicto forestal a un ecosistema forestal primario o secundario maduro, compuesto principalmente por especies arbóreas propias del hábitat junto al que ha compartido los procesos evolutivos, y durante éstos ha quedado aislado de los bosques de su entorno por al menos diez veces la distancia de dispersión natural de sus semillas, y con una superficie inferior a las 50 ha (Peri \& Ormaechea, 2013). Es decir, son comunidades marginales, separadas de otros bosques que forman una masa boscosa continua hacia el Oeste. También existen antecedentes de poblaciones de $N$. antarctica que forman relictos a lo largo del río Gallegos (23 relictos de uno o más árboles) con una dispersión agámica (vegetativa) a larga distancia promovida por eventos de crecida del río (Peri et al. 2013).

$N$. antarctica es un árbol caducifolio que se distribuye en Chile y Argentina desde los 36³0' S hasta los $56^{\circ} \mathrm{S}$. Entre los Nothofagus de América del Sur es la especie que presenta la mayor amplitud ecológica, adaptada a condiciones ambientales extremas de profundidad y permeabilidad del suelo, múltiples rangos de temperatura, precipitaciones y regímenes de heladas (Donoso et al. 2006). Desde el siglo pasado estos bosques han sido sometidos a diferentes usos como son el aprovechamiento forestal, la ganadería ovina y bovina. Asimismo, han sido afectados por distintos tipos de disturbios como son incendios, introducciones de especies, mortandad o daños por sequía, entre otros, lo que ha llevado a un deterioro progresivo de estos ecosistemas.

La diversidad de plantas vasculares de los bosques dominados por $N$. antarctica en la actualidad es una consecuencia de los múltiples procesos que han operado como fuerzas de cambio sobre las comunidades naturales originarias (Halffter \& Moreno, 2005). En este sentido, los índices de diversidad son métodos simples y de fácil interpretación (Hill, 1973; Moreno, 2001), que resumen mucha información en un solo valor. Permiten hacer comparaciones rápidas y sujetas a comprobación estadística entre la diversidad de distintos hábitats, con importantes implicancias en el monitoreo ambiental y el manejo de conservación (Magurran, 1988; Halffter, 1998). Existen tres clases: diversidad alfa $(\alpha)$ o diversidad dentro del hábitat, diversidad beta $(\beta)$ o diversidad entre hábitats, y diversidad gamma $(\gamma)$, que se refiere a un grupo de hábitats, al paisaje completo, compuesta de alfa y beta (Whittaker, 1972). Además, es importante considerar la separación de diversidad beta en sus dos componentes; el recambio efectivo que pondera las diferencias en la composición de especies por ganancia o pérdida de éstas (Lennon et al. 2001, Carvalho et al. 2012) y la diferenciación de riqueza por anidamiento, que mide las diferencias absolutas en el número de especies (Harrison et al. 1992; Baselga \& JiménezValverde, 2007; Baselga, 2010). La comparación de ambos componentes puede reflejar la diversidad de nichos disponibles en distintos sitios de un mismo gradiente (Legendre, 2014).

Con el fin de estudiar los patrones de diversidad de plantas vasculares, se seleccionaron cinco localidades de estudio distribuidas en el gradiente latitudinal de la provincia de Santa Cruz. En cada localidad, se relevaron bosques relictuales $(\mathrm{R})$ dominados por $N$. antarctica y sus bosques continuos aledaños (A). Postulamos que debido a la fuerte influencia de la matriz de estepa, hay una mayor cantidad de especies de plantas vasculares en los relictos con respecto a los bosques continuos. Se prevé que en los relictos haya una pérdida de plantas vasculares propias de los bosques continuos, y una ganancia de especies propias de la estepa. Además se espera que el gradiente latitudinal se refleje en la disminución del número de especies conforme aumenta la latitud y que los ambientes $\mathrm{A}$ y $\mathrm{R}$ que se encuentran dentro de áreas protegidas (AP) presenten características diferenciales a aquellos bosques que se encuentran en las inmediaciones de estancias productivas (EP). 


\section{MATERIALES Y MÉTODOS}

Se seleccionaron cinco localidades en la provincia argentina de Santa Cruz (de 1 a 5; de Norte a Sur) (Fig. 1). El área de estudio abarcó un rango latitudinal de $467 \mathrm{~km}$, entre los $47^{\circ} 4^{\prime}$ y $51^{\circ}$ $5^{\prime}$ LS y un rango longitudinal de $85 \mathrm{~km}$, entre los $72^{\circ} 5^{\prime}$ y $71^{\circ} 3^{\prime}$ LO (Tabla 1 ).

En cada una de las cinco localidades se identificaron dos ambientes de $N$. antarctica: bosques relictuales $(R)$ y bosques continuos aledaños a similares latitudes (A). En cada ambiente (A y R) se instalaron tres unidades de muestreo lo que generó en total $\mathrm{N}=30$ unidades de muestreo. Cada unidad de muestreo consistió en una superficie circular de $2000 \mathrm{~m}^{2}$ donde se relevaron las plantas vasculares y se cuantificó la abundancia utilizando el método de Braun-Blanquet (Mueller-Dombois \& Ellenberg, 1974). Se colectaron ejemplares y se herborizaron para su identificación en laboratorio utilizando lupa y material bibliográfico de apoyo: colección Flora Patagónica tomo VIII, partes I, II, III, IV a y b, V, VI y VII (Correa, 1969, 1971, 1978, 1984a, 1984b, 1988a, 1988b, 1999). Se realizó una corroboración de las identificaciones mediante visitas al herbario de referencia del INTA EEA Santa Cruz y el herbario de la Cátedra de Diversidad de Plantas UNPSJB en Esquel. Para cada especie se enlistó además, la familia, el status según origen (Nativa. Endémica. Adventicia. Cosmopolita o Indefinido), el hábito de vida (Árbol Perenne. Arbusto Perenne. Hierba. Hierba Anual. Hierba Anual o Bianual. Hierba o Arbusto Perenne. Hierba o Enredadera Perenne. Hierba o Subarbusto Perenne. Hierba Perenne. Subarbusto Perenne. Indefinido) y su exclusividad de aparición en bosques $\mathrm{R}$ o $\mathrm{A}$, respectivamente (aquellas especies sin letra $\mathrm{A}$ o $\mathrm{R}$ corresponden a especies comunes a los dos ambientes). Para las actualizaciones de nombres científicos se utilizó el Catálogo de las Plantas Vasculares del Cono Sur (Zuloaga, 2018).

\section{Análisis de datos}

\section{Diversidad alfa}

A fin de caracterizar la diversidad alfa, se estudiaron los tres aspectos que se detallan a continuación.

(i) Riqueza específica (S): se calculó mediante

Tabla 1. Detalles de ubicación y referencias históricas de los sitios en estudio.

Nombre Localidad Historia de uso

Parque Nacional Los Glaciares Sec. Río Guanaco

Estancia Cancha Carrera

Reserva Provincial Punta Gruesa

Estancia Rincón de los Morros
- Con evidencia de fragmentación reciente.

-Entre 1910 y 1937 sus pobladores han basado su economía en la ganadería y la extracción de leña intensiva para la venta.

- En 1937 fue creado el Parque Nacional.

- Sin evidencia de fragmentación reciente.

- Habitada continuamente desde principios del siglo.

2 - Sus pobladores han basado su economía en la ganadería extensiva y la extracción de leña.

- En 1937 fue creado el Parque Nacional.

- Sin evidencia de fragmentación reciente.

- Habitada continuamente desde principios del siglo.

- Sus pobladores han basado su economía en la ganadería extensiva y la extracción de leña intensiva.

- Sin evidencia de fragmentación reciente.

4 - Habitada continuamente desde principios del siglo.

- En 2002 fue declarada área protegida provincial.

- Con evidencia de fragmentación reciente.

- Habitada continuamente desde principios del siglo.

- Sus pobladores han basado su economía en la ganadería extensiva y la extracción de leña intensiva. 


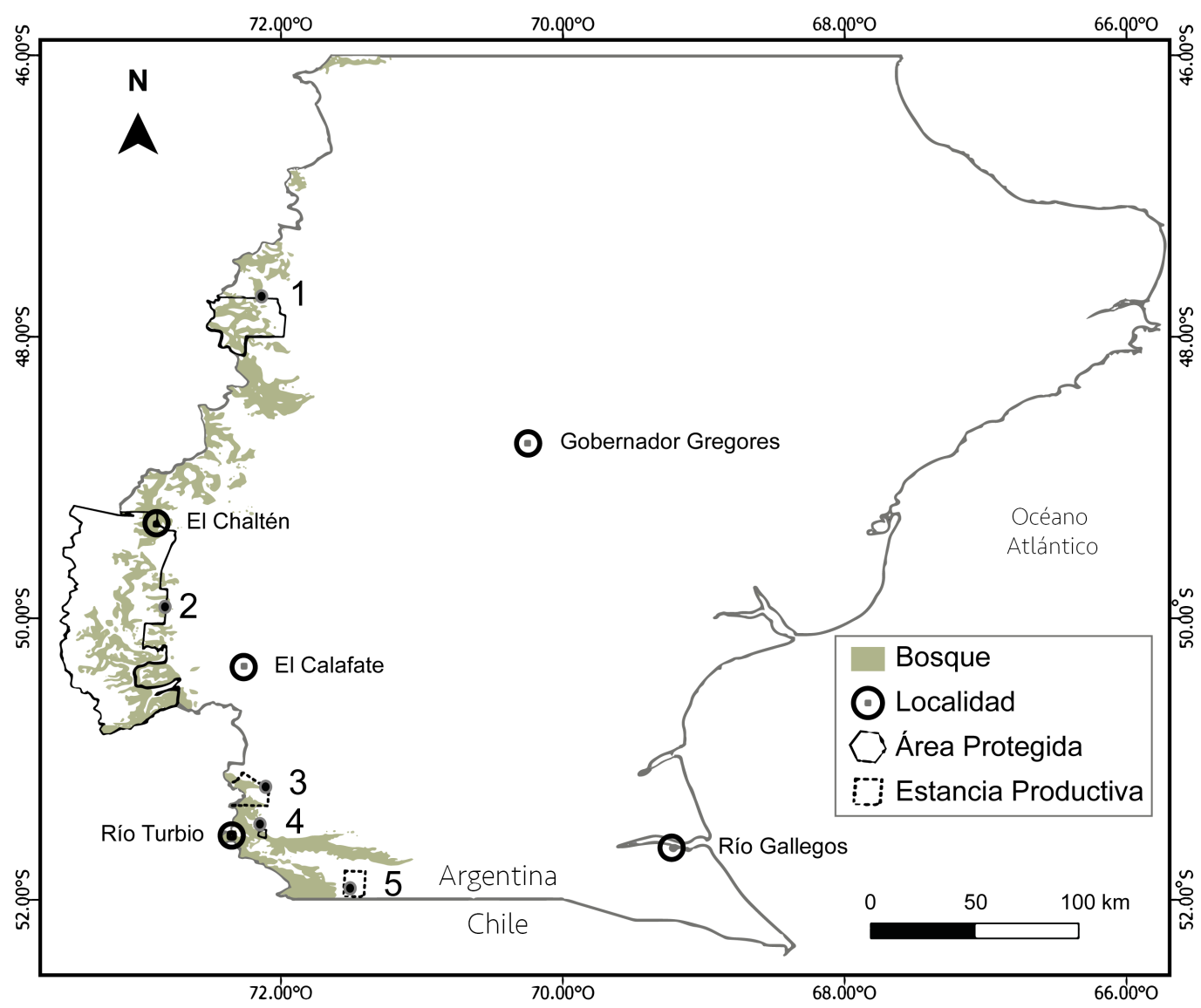

Fig. 1. Distribución geográfica de los sitios de estudio: 1) Parque Nacional Perito Moreno,

2) Parque Nacional Los Glaciares - Seccional Río Guanaco, 3) Estancia Cancha Carrera,

4) Reserva Provincial Punta Gruesa y 5) Estancia Rincón de los Morros. El vector del límite internacional oficial fue descargado del SIG-250 del Instituto Geográfico Nacional de Argentina (IGN).

la cuantificación del número de especies presentes en cada unidad de muestreo.

(ii) Índice Shannon $\left(H^{\prime}\right)$ : se calculó mediante la ecuación 1. Éste adquiere valores positivos entre cero, cuando hay una sola especie, y el logaritmo natural de $\mathrm{S}$, cuando todas las especies están representadas por el mismo número de individuos (Magurran, 1988; Moreno, 2001).

$H^{\prime}=-\sum p_{i} \times \ln \left(p_{i}\right)$

Donde pi es la proporción de individuos de la especie i respecto al total de individuos calculada como: $n_{i} / N$. Donde $n_{i}$ : número de individuos de la especie $\mathrm{i}$; $\mathrm{N}$ : número total de individuos de todas las especies.

Para los efectos de comparar la riqueza (S) y la diversidad alfa $\left(H^{\prime}\right)$ en relictos y en bosques continuos aledaños se realizaron ANOVAs de dos vías con un diseño en bloques, donde los factores analizados fueron AMBIENTE (A) con dos niveles: A y $\mathrm{R}$, y LOCALIDAD (L): con 5 niveles: 1, 2, 3,4 y 5 . Se tomaron tres repeticiones dentro de cada par AMBIENTE-LOCALIDAD. Cuando se encontraron diferencias estadísticamente significativas se realizaron a posteriori pruebas de Tukey. Los datos fueron sometidos inicialmente a la prueba de normalidad de Shapiro-Wilk modificada por Rahman y Govindarajulu (1997), y a la prueba de homocedasticidad de varianzas de Levene (Montgomery, 1991).

(iii) Curvas de acumulación de especies observadas $\left(S_{o b s}\right.$ - Mean Runs): representan la frecuencia acumulada de especies observadas 
(eje y) al añadir sucesivas unidades de muestreo (n) (eje $\mathrm{x}$ ) y se obtuvieron utilizando el programa EstimateS win8 (Gotelli \& Colwell, 2001) mediante la metodología propuesta por Jiménez-Valverde \& Hortal (2000). El ajuste de la ecuación a la curva de acumulación se analizó a través del coeficiente de determinación $\mathrm{R}^{2}$. El análisis arrojó los parámetros: a (tasa de incremento de nuevas especies al comienzo del inventario) y $\mathrm{b}$ (parámetro relacionado con la forma de la curva) que fueron utilizados para calcular la pendiente al final de la curva, y evaluar así la calidad del inventario. También se obtuvo la pendiente de Clench (ecuación 2) y la riqueza máxima teórica (ecuación 3).

$$
m=a /(1+b \times n)^{2}
$$

$S_{\text {máx téńrica }}=a / b$

Al comparar $S_{\text {máx teótica }}$ con el número de especies registradas $\left(S_{o b s}\right)$, se evaluó la calidad del muestreo. La pendiente de la curva $(\mathrm{m})$ cuando el número de muestreos es máximo (n), asume valores $<0,1$ si es poco probable que puedan añadirse nuevas especies al incrementar el número de muestreos (Jiménez-Valverde \& Hortal, 2000). Otra forma utilizada para medir la calidad del inventario es mediante la proporción de flora registrada que se calcula a través de la ecuación (4).

$$
\left(S_{\text {obs }} /(a / b)\right) \times 100
$$

Por último, se obtuvo el número medio de especies para cada unidad de muestreo $\left(S_{n}\right)$ (ecuación 5).

$S_{n}=a \times n /(1+b \times n)$

\section{Diversidad beta}

A fin de caracterizar la diversidad beta, se estudiaron los tres aspectos que se detallan a continuación.

(iv) Diversidad beta global - índice de disimilitud de Sorensen $\left(\beta_{\text {sor }}\right)$ : permite describir la diferenciación espacial y las diferencias en riqueza de especies entre las comunidades, es decir que explica todas las diferencias espaciales de composición en comunidades sin discriminar en sus dos componentes (Lennon et al. 2001; Koleff et al. 2003; Baselga, 2010). Relaciona el número de especies en común con las especies exclusivas de cada ambiente (A y R) (ecuación 6).

$\beta_{\text {sor }}=(a+b) /(2 c+a+b)$

Donde $\mathrm{a}=$ número de especies exclusivas del ambiente $\mathrm{A} ; \mathrm{b}=$ número de especies exclusivas del ambiente $\mathrm{R} ; \mathrm{y} \mathrm{c}=$ número de especies comunes para ambos ambientes (A y $\mathrm{R}$ ).

(v) Recambio efectivo - índice de disimilitud de Simpson $\left(\beta_{\text {sim }}\right)$ : refleja las diferencias en la composición de especies entre comunidades atribuibles a la sustitución (turnover o recambio) de unas especies por otras. Expresa el número de sustituciones entre dos ambientes en relación con el número de especies del ambiente más pobre en especies. $\beta_{\text {sim }}$ aumenta con la creciente diferencia de riqueza (Lennon et al. 2001) (ecuación 7).

$\beta_{\text {sim }}=\left(\min _{(a, b)}\right) /(c+\min (a, b))$

Donde $\min _{(a, b)}=$ mínimo número de especies exclusivas en cualquiera de los ambientes (A y $\mathrm{R}$ ); y $\mathrm{c}=$ número de especies comunes para ambos ambientes (encontradas tanto en A como en R).

(vi) Diferenciación de riqueza - índice de anidamiento $\left(\beta_{\text {nes }}\right)$ (Baselga, 2010): se considera responsable de explicar sólo la disimilitud de riqueza cuando los ambientes están anidados, es decir, cuando los ambientes tienen al menos una especie común ( $c>0$ ), o sea que $\beta_{\text {nes }}=\beta_{\text {sor }}-\beta_{\text {sim }}$, o como lo indica su equivalente matemático representado en la ecuación 8.

$$
\begin{aligned}
& \beta_{n e s}=\left(\max _{(a, b)}-\min _{(a, b)}\right) /\left(2 c+\max _{(a, b)}+\right. \\
& \left.\min _{(a, b)}\right) \times\left(c / c+\min _{(a, b)}\right)
\end{aligned}
$$

Donde $\min _{(a, b)}=$ mínimo número de especies exclusivas en cualquiera de los ambientes (A y R), $\max _{(\max )}=$ máximo número de especies exclusivas en cualquiera de los ambientes ( $\mathrm{A}$ y $\mathrm{R}$ ), a = número de especies exclusivas del ambiente $\mathrm{A}(\mathrm{A}) ; \mathrm{b}=$ número de especies exclusivas del ambiente $\mathrm{B}(\mathrm{R})$; y $\mathrm{c}=$ número de especies comunes para ambos ambientes (A y R). 


\section{Análisis multivariados}

Por último, se realizó un análisis de redundancia (RDA) (ter Braak, 1995) a fin de estudiar la relación entre las variables de la diversidad de plantas vasculares con otras variables ambientales analizadas en las unidades muestrales.

a) Variables relacionadas al sitio de estudio

En cada unidad de muestreo se registró el estado del rodal según la evidencia de disturbios antrópicos (incendios, aprovechamiento y ganadería), y mediante la utilización de transectas de 15 m de longitud y 150 puntos de observación, se calculó el porcentaje de la cobertura del suelo por: suelo desnudo, hojarasca, vegetación o residuo forestal. Con cinta métrica se midió el espesor de la hojarasca y con clinómetro se midió la pendiente.

b) Variables relacionadas a la estructura forestal

En individuos de N. antarctica que superaban $1,3 \mathrm{~m}$ de altura se registraron las siguientes variables dasométricas: densidad (ind/Ha), DAP $(\mathrm{cm})$, tipo de fuste (unifustal o multifustal), estado vital de copas y la clase social de copa. Para evaluar el estado vital de las copas se asignó visualmente una de cuatro categorías según la proporción de follaje vivo en la copa (Vívida; copa completamente viva. Sana; tres cuarto copa viva. Medianamente viva; media copa viva. Seca; sólo un cuarto de la copa viva). Por su parte, la clase social de copa se estimó a través de la posición relativa y el tamaño de la copa de cada individuo en el estrato vertical, se asignó una de cuatro categorías (Dominante. Codominante. Intermedio. Suprimido).

Para evaluar la densidad de la regeneración, se instalaron 4 sub-parcelas de $1 \mathrm{~m}^{2}$ dentro de las parcelas mayores de $500 \mathrm{~m}^{2}$. Se relevó el número de plántulas (menores a un año) y de renovales (> 1 año y menos de 1,3 $\mathrm{m}$ de altura).

El porcentaje de cobertura de copas de cada unidad de muestreo se obtuvo mediante 25 imágenes cenitales capturadas a un metro del suelo. Los puntos fotografiados estuvieron dispuestos en cuatro radios desde el centro de la parcela hacia la periferia y separados entre sí por $3 \mathrm{~m}$. Posteriormente el procesamiento de las imágenes se realizó con el ImageJ(C) (Image J 1.44; Rasband, 2011).

c) Variables edáficas

En cada unidad de muestreo se tomaron al azar, cinco submuestras de suelo con barreno de suelo de $5 \mathrm{~mm}$ de diámetro, a una profundidad de 20 - $30 \mathrm{~cm}$. Se utilizó el método de muestra compuesta.

Las muestras de suelo fueron enviadas al Laboratorio de Suelos del INTA Chubut para su análisis completo. Las propiedades fisicoquímicas analizadas fueron: i) Textura determinada a través del método densimétrico de Bouyoucos y tamizado de las fracciones de arena. ii) $\mathrm{pH}$ obtenido por medición potenciométrica en pasta saturada con agua. iii) Materia orgánica (MO) (\%) y iv) carbono orgánico (C) fueron determinados según el Método Walkley y Black (1934). Las propiedades de Fertilidad analizadas fueron: i) Nitrógeno total (N) determinado por el Método Kjeldahl IRAMSAGyP 29572 (2011). ii) Fósforo disponible (P; ppm) determinado por el método de Olsen (1954). iii) Cationes intercambiables de Potasio (K) medidos con una solución extractante de acetato de amonio, posteriormente el $\mathrm{K}$ se determinó por espectrofotometría de llama.

\section{d) Variables bioclimáticas}

Los parámetros bioclimáticos para cada unidad de muestreo derivaron del conjunto de datos climáticos globales de WorldClim (www. worldclim.org, Hijmans et al. 2005). Éste contiene superficies geográficas globales para diecinueve parámetros climáticos diferentes que describen la precipitación, la temperatura y la combinación de estos parámetros con una resolución de $0,008333^{\circ}$ (aproximadamente $1 \mathrm{~km}$ ). A continuación se detalla cada uno: BIO1=Temperatura media anual, BIO2=Intervalo diurno medio (Promedio de la temperatura mensual (temperatura máxima - temperatura mínima)), BIO3=Isotermalidad (BIO2 / BIO7) (* 100), BIO4=Temporada de temperatura (desviación estándar * 100), BIO5=Temperatura máxima del mes más cálido, BIO6=Temperatura mínima del mes más frío, $\mathrm{BIO} 7=$ Rango de temperatura anual (BIO5-BIO6), 
BIO8=Temperatura media del cuarto más húmedo, BIO9=Temperatura media del cuarto más seco, BIO10=Temperatura media del cuarto más cálido, BIO11=Temperatura media del cuarto más frío, BIO12=Precipitación anual, BIO13= Precipitación del mes más húmedo, BIO14=Precipitación del mes más seco, $\mathrm{BIO} 15=$ Estacionalidad de la precipitación (Coeficiente de variación), BIO16=Precipitación del cuarto más húmedo, BIO17=Precipitación del cuarto más seco, BlO18=Precipitación del cuarto más cálido y BIO19=Precipitación del cuarto más frío.

Los cálculos fueron realizados usando PCORD vs. 5 (Mc Cune \& Mefford, 1999). Se asumió que las relaciones entre la diversidad de plantas vasculares y las variables ambientales estudiadas eran de tipo lineal (ter Braak, 2002) y que la variable espacial latitudinal podía estar enmascarando las asociaciones Suelo - Clima. Se procedió entonces a ejecutar la latitud (localidad) como covariable y la cobertura - abundancia de plantas como variable respuesta. Las variables más significativas se determinaron utilizando el método lambda de Wilk (Butler \& Wood, 2004; De Sá, 2007).

\section{RESULTADOS}

\section{Diversidad alfa}

El número total de especies de plantas vasculares registrado fue de 152 , de las cuales $106(69,7 \%)$ fueron encontradas tanto en A como en R. Por otro lado, 19 especies (12,5\%) se hallaron exclusivamente en los ambientes $\mathrm{R}$ y 27 especies $(17,8 \%)$ en los ambientes A. Las especies identificadas se encuentran distribuidas en 41 familias. La familia más representada fue Asteraceae con 33 especies (22\%), sobresaliendo el género Senecio sp. con 7 especies. Seguida en importancia por la familia Poaceae con 15 especies (10\%) (Anexo 1).

El $80 \%$ de las plantas vasculares resultaron ser nativas, el $14 \%$ de las especies exóticas y un $6 \%$ no fue identificado. Asimismo, se registró un $85 \%$ de especies herbáceas y un $14 \%$ de especies de hábito leñoso. En los bosques continuos (A) las plantas herbáceas más frecuentes fueron: Osmorhiza chilensis, Festuca pallescens, Rumex acetosella y Poa pratensis. Mientras que en los relictos (R) las herbáceas más frecuentes fueron: Festuca pallescens, Taraxacum officinale, Rumex acetosella y Armeria maritima. En el estrato arbustivo de los bosques continuos (A) las especies más frecuentes fueron: Berberis microphylla, Baccharis magellanica, Ribes cucullatum y Gaultheria mucronata. Mientras que en los relictos (R) fueron: Berberis microphylla, Senecio filaginoides, Baccharis magellanica y Gaultheria pumila.

En tanto la riqueza total en los bosques relictuales $(R)$ fue 125 especies y en los bosques continuos (A) fue 133 especies. El promedio de la riqueza de especies no presentó diferencias estadísticamente significativas $(p=0,2181)$ entre los ambientes $\left(\mathrm{S}_{\mathrm{R}, \mathrm{n}=5}=40 ; \mathrm{S}_{\mathrm{A}, \mathrm{n}=5}=37\right)$. Sin embargo, la riqueza varió significativamente entre localidades ( $p<0,0002$ ). Las principales diferencias se dieron entre la localidad 1, donde se registraron los valores más altos, y la localidad 5, donde se registraron los valores más bajos (Fig. 2). En tanto la interacción AMBIENTE-LOCALIDAD (AXL) fue significativa $(p=0,0015)$, resultando más ricos en biodiversidad los ambientes de menor latitud (localidad 1) y los relictos de las áreas protegidas (localidades 2 y 4). Los ambientes del extremo Sur presentaron menos riqueza de especies (localidad 5).

La diversidad alfa $\left(H^{\prime}\right)$ de plantas vasculares en los bosques relictuales $\left(\mathrm{H}_{\mathrm{R}}=3,40\right)$ fue similar a la de los bosques continuos $\left(\mathrm{H}_{\mathrm{A}}=3,36\right)(\mathrm{p}=0,585)$. Sin embargo, la diversidad de plantas vasculares (H) varió significativamente entre localidades ( $p$ $<0,0001)$. Las principales diferencias se dieron entre la localidad 1, donde se registraron los valores más altos, y la localidad 5, donde se registraron los valores más bajos. En tanto las localidades 2, 3 y 4 mostraron valores intermedios, siendo que las localidades dentro de áreas protegidas (localidades 2 y 4) no mostraron diferencias entre sí $(p<0,05)$ (Fig. 3). La interacción AMBIENTE-LOCALIDAD (AXL) fue significativa $(p=0,0016)$, resultando más diversos los relictos de menor latitud (localidade 1) y menos diversos los relictos del extremo Sur (localidad 5).

Las curvas de acumulación de especies observadas en ambos ambientes ( $\mathrm{R}$ y A, Fig. 4) se presentan prácticamente solapadas. Las tasas de incremento de nuevas especies en los relictos (R) al comienzo de los inventarios fueron $a=50,9$ y en los bosques continuos a $=40,2$. El parámetro $\mathrm{b}$, relacionado con la forma de la curva, resultó 


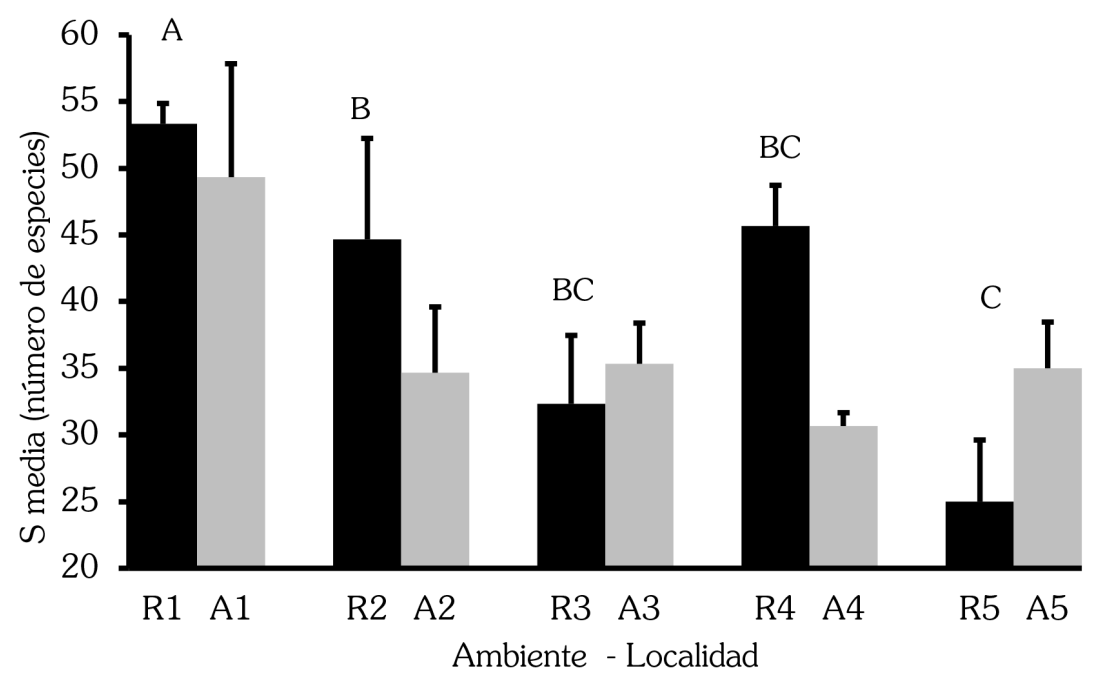

Fig. 2. Riqueza de especies $(\mathrm{S})( \pm \mathrm{EE})$. Ambientes: bosque relicto $(\mathrm{R})$ y bosque continuo aledaño (A). Localidades: 1) Parque Nacional Perito Moreno, 2) Parque Nacional Los Glaciares - Río Guanaco, 3) Estancia Cancha Carrera, 4) Reserva Provincial Punta Gruesa y 5) Estancia Rincón de los Morros. Las barras indican error estándar. Diferentes letras muestran diferencias significativas entre localidades según prueba de Tukey a un nivel $p=0,05$.

0,35 y 0,24 para $\mathrm{R}$ y $\mathrm{A}$ respectivamente. Cuando se compararon las curvas se observó que para la unidad muestral $\mathrm{n}=1$, la riqueza de especies fue de aproximadamente 41 en los relictos mientras que en los bosques continuos la riqueza de especies fue ligeramente menor, alrededor de 37. A continuación el modelo (1) describe la curva de acumulación de especies en los bosques relictuales y el modelo (2) describe la curva de acumulación de especies en los bosques continuos aledaños.

$$
S_{n} R=50,9 \times n /(1+0,35 \times n) \quad R^{2}=0,99
$$

$S_{n} R=40,2 \times n /(1+0,24 \times n) \quad R^{2}=0,99$

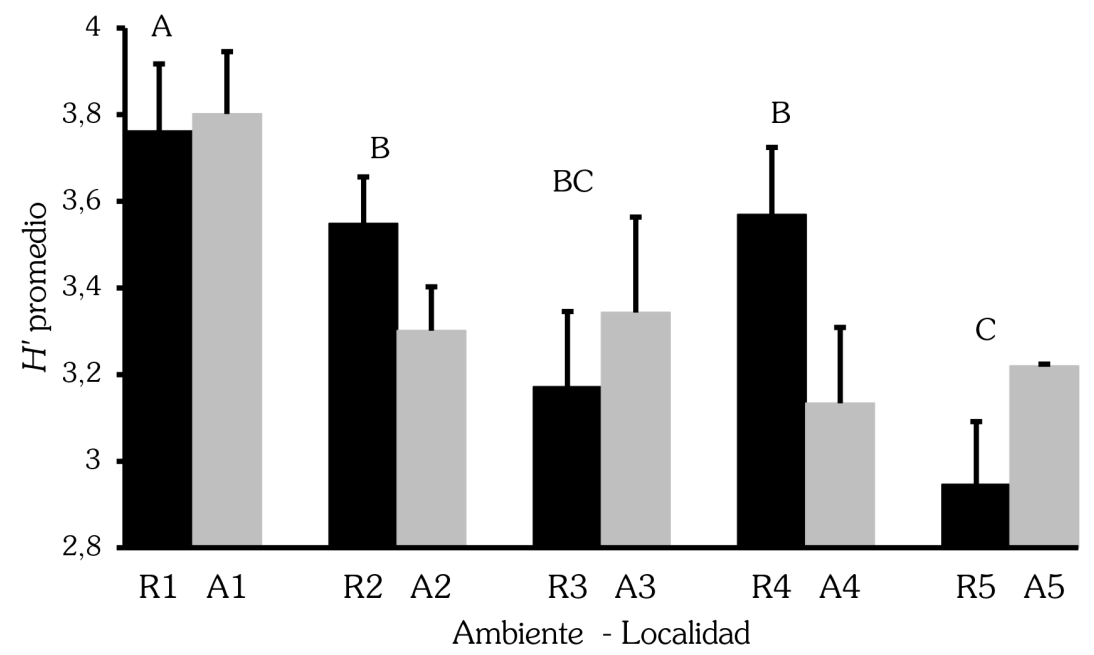

Fig. 3. Índice de Shannon-Wiener ( $\left.\mathrm{H}^{\prime}\right)$ ( $\left.\pm \mathrm{ES}\right)$. Ambientes: bosque relicto $(\mathrm{R})$ y bosque continuo aledaño (A). Localidades: 1) Parque Nacional Perito Moreno, 2) Parque Nacional Los Glaciares - Río Guanaco, 3) Estancia Cancha Carrera, 4) Reserva Provincial Punta Gruesa y 5) Estancia Rincón de los Morros. Las barras indican error estándar. Diferentes letras muestran diferencias significativas entre localidades según prueba de Tukey a un nivel p=0,05. 


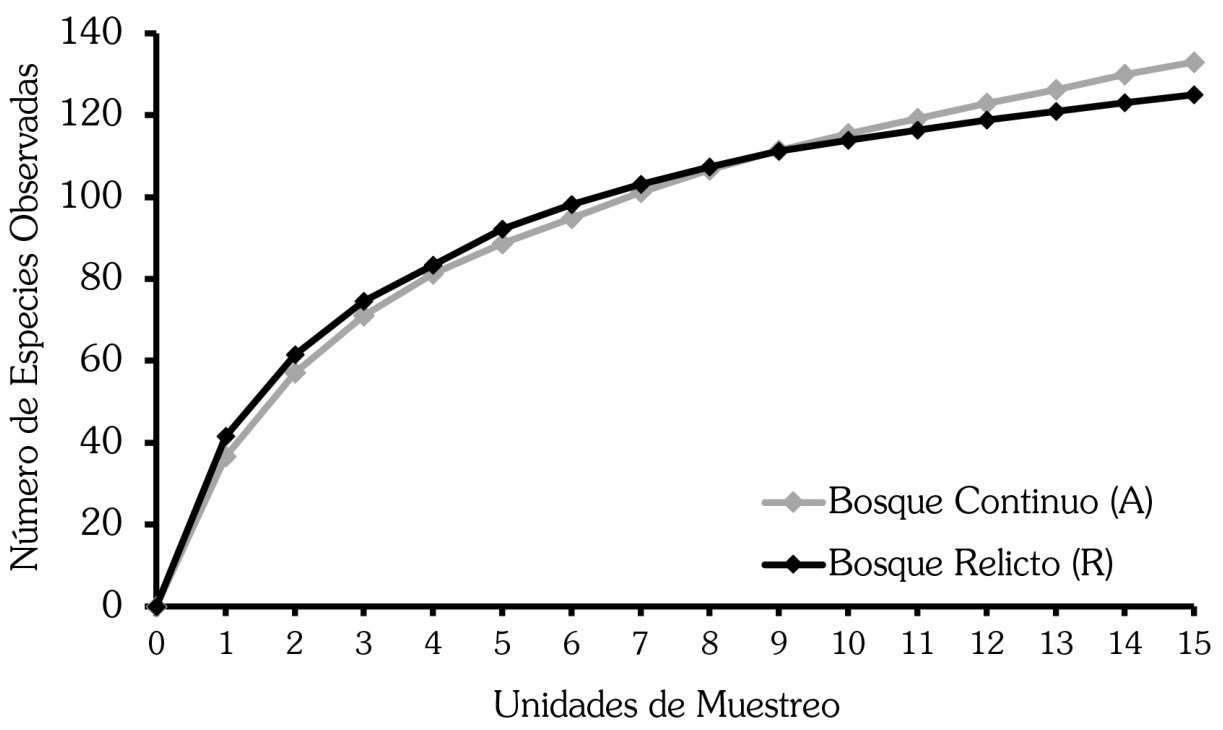

Fig. 4. Curvas de acumulación de especies para bosques relictos (negro) y bosques aledaños continuos (gris) de $N$. antarctica.

Los altos coeficientes de determinación $\left(\mathrm{R}^{2}\right)$ que presentan ambos modelos indican que los modelos están fuertemente ajustados a las curvas de acumulación. Para la curva de acumulación de especies obtenida en los relictos la pendiente $\mathrm{m}=$ 1,33. En el caso de la curva de acumulación de especies de los bosques continuos la pendiente resultó ser $\mathrm{m}=1,85$. Finalmente, se estimó que la proporción de flora registrada fue del $90 \%$ en $\mathrm{R}$ y del $81 \%$ en $\mathrm{A}$ con un $\mathrm{n}=15$. Así, el número máximo de especies esperado resultó 147 y 164 especies para $\mathrm{R}$ y para A respectivamente.

Paralelamente se comparó la riqueza $(\mathrm{S})$ mediante la partición del ANOVA de acuerdo a la jurisdicción de cada localidad; ambientes dentro de áreas protegidas (AP; localidades 1, 2 y 4) y ambientes dentro de estancias productivas (EP; localidades 3 y 5). En el primer caso (AP), S presentó diferencias estadísticamente significativas entre ambientes $(p=0,0006)$ y entre localidades $(p=0,0005)$. La diferencia principal se dio entre la localidad 1 , donde se registraron los valores más altos, y las localidades 2 y 4 que no mostraron diferencias entre sí $(p<0,05)$. La interacción AMBIENTELOCALIDAD (AXL) no mostró diferencias significativas ( $p=0,1761)$.

En el segundo caso, ambientes dentro de estancias productivas (EP), $S$ no mostró diferencias estadísticamente significativas entre los ambientes $(p=0,0534)$, ni entre las localidades $(p=0,2498)$, ni en la interacción AMBIENTE-LOCALIDAD (AXL) ( $p=0,3248)$.

\section{Diversidad beta}

Se resumen los valores de los indices de diversidad beta global $\left(\beta_{\text {sor }}\right)$ y sus complementos $\left(\beta_{\text {sim }}\right.$ y $\beta_{\text {nes }}$ ) (Tabla 2$)$. Las mayores disimilitudes

Tabla 2. Índices de disimilitud entre ambientes de bosques continuos (A) y bosques relictuales (R). $\beta_{\text {sor }}=$ Diversidad beta global - Índice de disimilitud de Sorensen;

$\beta_{\text {sim }}=$ Recambio efectivo - índice de disimilitud de Simpson;

$\beta_{\text {nes }}=$ Diferenciación de riqueza - índice de anidamiento.

\begin{tabular}{cccc}
\hline Localidad & $\beta_{\text {sor }}$ & $\beta_{\text {sim }}$ & $\beta_{\text {nes }}$ \\
\hline 1 & 0,24 & 0,24 & 0,00 \\
2 & 0,44 & 0,38 & 0,06 \\
3 & 0,37 & 0,28 & 0,09 \\
4 & 0,40 & 0,26 & 0,14 \\
5 & 0,24 & 0,08 & 0,16 \\
\hline A-R Total & 0,18 & 0,03 & 0,12 \\
\hline DS & 0,09 & 0,11 & 0,07 \\
\hline ES & 0,04 & 0,05 & 0,03 \\
\hline Promedio & 0,34 & 0,25 & 0,09 \\
\hline
\end{tabular}


globales entre ambientes se encuentran en las localidades 2 y 4 , donde prácticamente hay un $50 \%$ de disimilitud entre los ambientes. En tanto, en la localidad 3 hay menos disimilitud y en las localidades 1 y 5 los ambientes A y R tienen composiciones de especies relativamente similares. Por su parte, la partición $\beta_{\text {sim }}$ muestra de manera general una relación inversa con la latitud, mientras que $\beta_{\text {nes }}$ aumenta con ésta.

\section{Análisis multivariados}

Las variables ambientales que más explicaron la diversidad de plantas vasculares fueron las variables edáficas de $\mathrm{C}, \mathrm{N}, \mathrm{P}, \mathrm{K}, \mathrm{pH}$ y $\mathrm{MO}$, y cuatro de los diecinueve parámetros bioclimáticos (BIO1, BIO8, BIO12 y BIO15) (Fig.5).

El $15,4 \%$ de la variación florística y el $44,8 \%$ de la relación especies-ambiente son explicadados

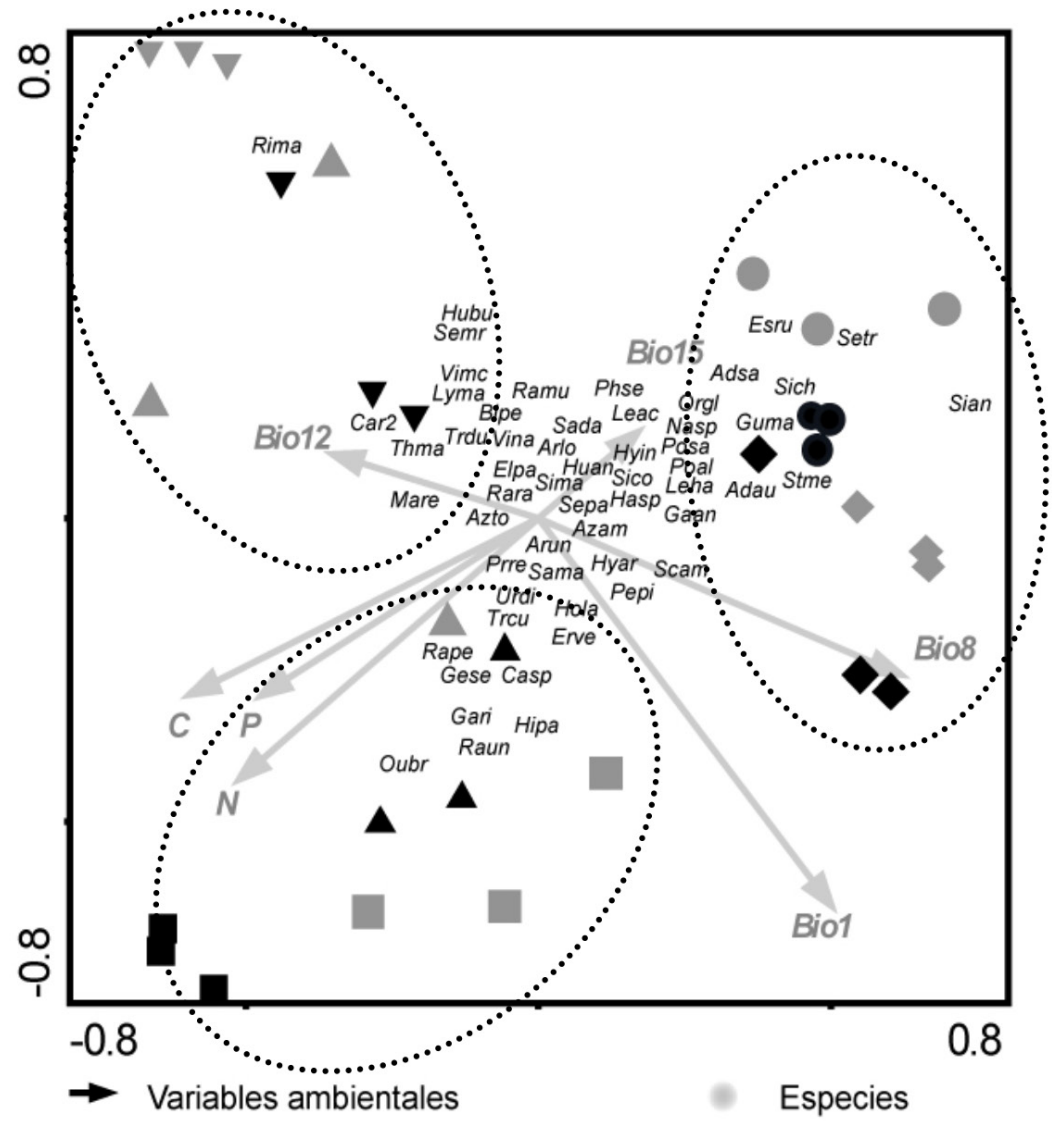

Unidades Muestrales (Ambiente / Localidad)

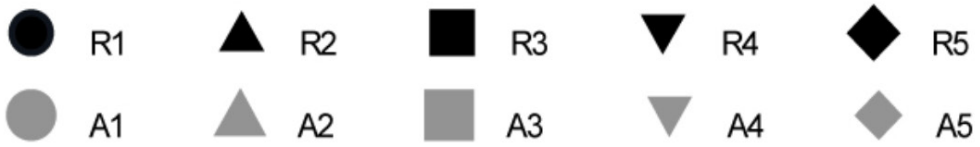

Fig. 5. Diagrama triplot de ordenación RDA. Las flechas indican variables ambientales; edáficas $(\mathrm{N}, \mathrm{P}$ y $\mathrm{C})$ y Bioclimáticas $(\mathrm{BIO} 1=$ Temperatura media anual, $\mathrm{BIO} 8=$ Temperatura media del cuarto más húmedo, BIO12 = Precipitación anual y BIO15 = Estacionalidad de la precipitación - coeficiente de variación). Abreviaturas de las especies de plantas vasculares según Apéndice. Los ítems representan las unidades muestrales; el color de los símbolos indica el tipo de ambientes: negros = relictos; grises = bosques continuos aledaños. Las formas de cada símbolo indican una localidad diferente: círculos $=1$; triángulos $=2$; cuadrados $=3$; triángulos invertidos $=4 ; y$ rombos $=5$. Eigenvalue eje 1, 0,085; eje 2, 0,056. 
por los dos primeros ejes. La Prueba de Monte Carlo resultó significativa $(\mathrm{P}<0,01)$ para todos los ejes canónicos. Asimismo el RDA mostró una fuerte relación entre las especies y el ambiente con correlación (r) especies-ambiente de 0,92 en el primer eje y 0,94 en el segundo.

El análisis de RDA muestra que las unidades muestrales se separaron en tres grupos (líneas de puntos). El eje 1 está principal y negativamente correlacionado con el $\mathrm{N}$ y luego con el $\mathrm{C}$ y el $\mathrm{P}$, mientras que se correlaciona en forma positiva con la Temperatura media anual (BIO1) y posteriormente con la Temperatura media del cuarto más húmedo (BIO8). Esto significa que las unidades de muestreo situadas en el lado derecho del primer eje (localidades 1 y 5) se caracterizan por temperaturas más altas y las del lado izquierdo presentan mayores valores de nutrientes en el suelo. El segundo eje se correlaciona negativamente con estas variables (localidades 2, 3 y 4) y se correlaciona en forma positiva con la Precipitación anual (BIO12) y su estacionalidad (BIO15).

\section{DISCUSIÓN}

La diversidad de plantas vasculares de los bosques de $N$. antarctica analizados tiene un fuerte componente de especies autóctonas y herbáceas propias de la estepa, así como otras especies propias del bosque patagónico. Esta composición es similar a la encontrada en otros ambientes de transición (Ezcurra \& Brion, 2005). Sin embargo, los relictos presentan mayor frecuencia de algunas especies más características de ambientes abiertos, mientras que los bosques continuos aledaños presentan mayor frecuencia de algunas especies más características de ambientes cerrados.

Cuando se analizó la diversidad alfa ( $\mathrm{S}$ y $H^{\prime}$ ) no se detectaron diferencias significativas entre la comunidad de plantas vasculares de los bosques relictos (R) y los bosques continuos (A). En cambio, sí hubo variación en la diversidad alfa entre localidades. Contrariamente a lo esperado, las curvas de acumulación de especies muestran una leve tendencia hacia una mayor riqueza total de especies en los bosques continuos con respecto a los relictos, incluso el valor de la pendiente calculada (m) indica que todavía es posible agregar nuevas especies al incrementar el número de muestreos en A. Sin embargo, se detectó una tendencia hacia una mayor riqueza de especies en los relictos de las localidades 1,2 y 4 con respecto a los bosques continuos de cada una de estas localidades. En la actualidad estos tres pares de ambientes se encuentran con una baja actividad humana y protegidos bajo figura legal desde los años 1937, 1937 y 2002 respectivamente. Por otro lado, en las localidades 3 y 5 la riqueza fue mayor en los bosques continuos que en los bosques relictos. Esto puede explicarse debido a que ambos pares de ambientes están sometidos a una alta presión de uso por ganadería y aprovechamiento forestal por encontrarse dentro de estancias productivas. Así, los $\mathrm{R}$ menos disturbados presentan mayor diversidad de plantas que los $\mathrm{R}$ más disturbados. Estos resultados coinciden con las observaciones de otros trabajos similares en los que se ha evidenciado que bosques de Patagonia sin uso ganadero presentan mayores valores de cobertura, riqueza y diversidad de plantas vasculares nativas que los bosques de uso productivo (Armesto, 1995; Conticello et al. 1996). Considerando que tanto los bosques relictos como los continuos aledaños en cada localidad son sometidos a similares usos antrópicos, estos resultados permiten interpretar que los relictos son más sensibles a los disturbios que los bosques continuos.

En relación con el análisis de variación de la diversidad de plantas vasculares en el gradiente latitudinal Norte-Sur, acorde a lo esperado los menores valores de diversidad de plantas vasculares se registraron en la localidad más austral $\left(5 ; 51^{\circ} 5^{\prime}\right.$ LS), mientras que los mayores valores se registraron en la localidad ubicada a menores latitudes $\left(1 ; 47^{\circ} 4^{\prime}\right.$ LS). En tanto en las latitudes intermedias este patrón fue menos marcado, tomando valores intermedios en las localidades 2 y 4 , y más bajos en 3 que en 4 contrariamente a lo esperado, ya se ha mencionado que las localidades 3 y 5 experimentan mayores presiones de uso, lo que podría explicar este patrón. Esto tiene concordancia con estudios llevados a cabo en distintos lugares del mundo, donde los valores de riqueza de especies se ven fuertemente influenciados por la latitud y clima (Fischer, 1960; Pianka, 1966; Stehli et al. 1969; Stevens, 1989; Villagrán, 1995). En la mayoría de los grupos de organismos, el número promedio de especies en un área específica de muestreo alcanza su máximo 
en latitudes tropicales y decrece de manera muy marcada, tanto hacia el Norte como al Sur conforme se acerca a los polos (Badii et al. 2008).

Por otro lado, la comparación de diversidad entre ambientes basada en los índices de disimilitud que contempla la composición de especies indicó similitud/disimilitud muy variable entre A y $\mathrm{R}$ en las cinco localidades, el valor del índice de diversidad beta global $\left(\beta_{\text {sor }}=0,18\right)$ indica una baja similitud en la diversidad de plantas vasculares entre los bosques A y R (Baselga, 2010). Los valores de disimilitud global de diversidad $\left(\beta_{\text {sor }}\right)$ muestran que los ambientes A y $\mathrm{R}$ más similares entre sí se encuentran en las localidades ubicadas en el extremo Norte (localidad 1) y en el extremo Sur (localidad 5) del área en estudio, ambas áreas con evidencia de fragmentación reciente. Mientras que las mayores disimilitudes entre A y $\mathrm{R}$ se encontraron en las localidades 2 y 4 , coincidiendo con la situación de los relictos más diversos situados dentro del sistema de áreas protegidas.

En el análisis de los componentes de la diversidad beta global predominó el componente de recambio efectivo de especies $\left(\beta_{\text {sim }}\right)$ en todas las localidades, con excepción de la localidad más austral (localidad 5) del área de estudio, donde predominó el componente de diferenciación de especies por anidamiento $\left(\beta_{\text {nes }}\right)$. Por lo tanto, en este caso la diversidad beta global se encuentra determinada en mayor medida por el recambio efectivo de especies $\left(\beta_{\text {sim }}\right)$ y a pesar de la existencia de un patrón anidado en los ambientes estudiados, éste no tuvo gran incidencia en la diversidad local. Asimismo, $\beta_{\text {nes }}$ presenta una relación positiva a lo largo del gradiente latitudinal; aumenta a medida que aumenta la latitud, mostrando una relación inversa con la diversidad alfa, que disminuye a lo largo de este gradiente.

$\mathrm{Al}$ encontrar un valor de $\beta_{\text {nes }}=0$ en la localidad ubicada en el extremo Norte (localidad 1), se puede interpretar que esta es la localidad donde las especies raras en términos de frecuencia son las que más aportan a la diversidad alfa. En el extremo Sur del gradiente (localidad 5) fue encontrado el mayor valor del índice beta por anidamiento $\left(\beta_{\text {nes }}\right.$ $=0,16)$, donde los valores de diversidad alfa son bajos, por lo que la mayoría de las especies son comunes en términos de frecuencia (CalderónPatrón et al. 2012). Considerando que la diversidad beta es un componente importante a la hora de establecer estrategias eficientes de conservación biológica (Scott et al. 1999), estos datos sugieren que los ambientes de la localidad más austral han perdido ordenadamente las especies que aún están presentes en las otras localidades del gradiente. Por lo que puede interpretarse como un sitio con bajo valor de conservación en comparación al resto (Rodríguez et al. 2003).

Cuando un ensamble de especies se presenta anidado puede deberse a diversas causas evolutivas, históricas o ambientales (Wright et al. 1997). El anidamiento que se observa particularmente en este sistema fragmentado y modificado por el uso humano, puede explicarse parcialmente por procesos de extinción local debidos a la reducción del área de distribución de las especies (Wright \& Reeves, 1992; Atmar \& Patterson, 1993) o por la diversificación de hábitats que genera la fragmentación (Honnay et al. 1999; Myklestad \& Sæetersdal, 2004). En este sentido, se expone que las condiciones ambientales propias de cada localidad y los disturbios antrópicos determinan la presencia de especies de estepa y de bosque. Estos resultados revelan que se trata de un sistema anidado sin dominancia ni exclusión de especies (Connell, 1978). Así se puede considerar que los componentes alfa y beta de la diversidad presentan variación espacial a lo largo del gradiente $y$, por lo tanto, están influyendo a la diversidad regional. El amplio rango de distribución geográfica de las especies compartidas por las localidades de cada extremo del gradiente estudiado (localidades 1 y 5) podría ser indicador del tipo de respuestas bioecológicas de las especies y denotar una gran vagilidad de éstas, frente a los cambios climáticos del pasado (Nekola \& White, 1999). En este sentido, las diferencias por reemplazo y por anidamiento varían según el gradiente latitudinal y, por lo tanto, las especies raras en términos de ocurrencia se presentan en localidades $\alpha$-diversas (localidad 1), mientras que especies comunes están presentes en todas las localidades (Rodríguez et al. 2003).

En este sentido, el análisis en conjunto de los diferentes niveles de diversidad, alfa $(\alpha)$ o diversidad dentro del hábitat y beta $(\beta)$ o diversidad entre hábitats, resulta crucial para profundizar en el conocimiento de los procesos ecológicos, los patrones de distribución observados en la naturaleza 
y aplicarlos en la conservación de la biodiversidad y el manejo de los ecosistemas (Legendre et al. 2005; Legendre, 2014).

Para establecer la relación entre las principales variables ambientales y la composición de la comunidad de plantas vasculares se realizó un análisis de redundancia (RDA). Este análisis de ordenación reveló que las variables explicativas más importantes fueron edáficas y bioclimáticas, explicando más del $90 \%$ de la varianza total. Los resultados no mostraron diferencias en la ordenación entre los pares de ambientes comparados en este trabajo ( $\mathrm{R}$ y $\mathrm{A}$ ), pero sí han demostrado cierta relación entre la composición de la comunidad de plantas vasculares y las localidades. El principal factor que relaciona a las localidades de baja similitud (beta bajos; localidad 1 y 5) es la temperatura. Mientras que los mayores contenidos de nutrientes en el suelo se relaciona a las localidades intermedias (2, 3 y 4). Asimismo existe una relación específica entre las características del suelo y el clima con las especies.

Finalmente, este trabajo demuestra que los relictos de $N$. antarctica son ecosistemas singulares que aportan a la heterogeneidad del paisaje. Se caracterizan por presentar una mayor sensibilidad a los disturbios antrópicos con respecto a los bosques continuos aledaños. Donde la diversidad de plantas vasculares se ve afectada tanto por la posición del bosque con respecto al ecotono bosque-estepa (hacia el Oeste o hacia el Este), como por la latitud y la historia de usos antrópicos. Al mismo tiempo se aporta información para la puesta en valor de los relictos de bosque nativo, que ante la falta de políticas efectivas que garanticen la gestión adecuada de los ambientes patagónicos, los usos intensivos tradicionales resultan en la actualidad una amenaza a la integridad de la diversidad. Estos disturbios antrópicos homogenizan los ecosistemas, por lo que resulta inminente la implementación de medidas que permitan su correcta conservación.

\section{AGRADECIMIENTOS}

En primera instancia se agradece a los acompañantes voluntarios que fueron muchos y muy importantes: Laura Ponce, Florencia Esnaola Comas, Celina Bertoni, Tomás de Hagen, Nicolás Abramson, Micaela Mazas, Hans Schulz,
Tomás Cassani, Pía Pacheco, Arian Ferstl, y muy especialmente a Rodrigo Clarke y Tiara Leotta.

Del mismo modo se expresan los profundos agradecimientos al equipo de trabajo: Pablo Peri, Ivonne Orellana, Vanessa Lencinas, Guillermo Martínez-Pastur y Sandra Casas; por último, a los representantes de las instituciones implicadas: Carlos Velarde, José María Barrios y Juan Carlos Ruiz (Consejo Agrario Provincial), Héctor Bahamonde, Sebastián Ormaechea, Verónica Gargaglione, Romina Lasagno y Eugenia Vivar (INTA EEA Santa Cruz), Juan Pablo Mayo y Carolina Peterson (Universidad Nacional de la Patagonia Austral), Roxana Giménez y Marianela Mirabelli (Administración de Parques Nacionales).

Este trabajo se materializó con financiamiento de la Ley Nacional N 26.331 "Prepuestos Mínimos de Protección Ambiental de los Bosques Nativos" y se incorpora al PI 1320 de la Universidad Nacional de la Patagonia San Juan Bosco.

\section{LITERATURA CITADA}

Armesto, J. J. (1995). Los bosques templados del sur de Chile y Argentina: una isla biogeográfica. Ecología de los bosques nativos de Chile, (1996) 23-28.

Atmar, W., \& Patterson, B. D. (1993). The measure of order and disorder in the distribution of species in fragmented habitat. Oecología, 96(3), 373-382.

Badii, M. H., Landeros, J., \& Cerna, E. (2008). Patrones de asociación de especies y sustentabilidad. Revista Daena (International Journal of Good Conscience), 3(1).

Baselga, A. (2010). Partitioning the turnover and nestedness components of beta diversity. Global Ecology and Biogeography, 19(1), 134-143.

Baselga, A., \& Jiménez-Valverde, A. (2007). Environmental and geographical determinants of beta diversity of leaf beetles (Coleoptera: Chrysomelidae) in the Iberian Peninsula. Ecological Entomology, 32(3), 312-318.

Blisniuk, P. M., \& Stern, L. A. (2005). Stable isotope paleoaltimetry: A critical review. American Journal of Science, 305(10), 
1033-1074.

Calderón-Patrón, J. M., Moreno, C. E., \& Zuria, I. (2012). La diversidad beta: medio siglo de avances. Revista mexicana de biodiversidad, 83(3), 879-891.

Carabelli, F., Jaramillo, M., \& Antequera, S. (2003). Cambios en la heterogeneidad del bosque nativo en la Patagonia Andina de Argentina y su impacto sobre la biodiversidad en los sectores de borde. Cuadernos de biodiversidad, $n^{\circ} 14$ (oct. 2003); pp. 1015.

Carvalho, J. C., Cardoso, P., \& Gomes, P. (2012). Determining the relative roles of species replacement and species richness differences in generating beta-diversity patterns. Global Ecology and Biogeography, 21(7), 760771.

Connell, J. H. (1978). Diversity in tropical rain forests and coral reefs. Science, 199(4335), 1302-1310.

Conticello, L., Gandullo, R., Bustamante, A., \& Tartaglia, C. (1996). Fitosociología de los bosques caducifolios del norte del Departamento Lácar y sur de Huiliches de la provincia de Neuquén (Argentina). Bosque, 17(2), 27-43.

Correa, M. N. (1969). Flora Patagónica. Tomo VIII Parte II. Typhaceae a Orchidaceae (excepto Gramineae). Colección Científica de INTA. Buenos Aires. Argentina.

Correa, M. N. (1971). Flora Patagónica. Tomo VIII Parte VII. Compositae. Colección Científica de INTA. Buenos Aires. Argentina.

Correa, M. N. (1978). Flora Patagónica. Tomo VIII. Parte III. Gramineae. Colección Científica de INTA. Buenos Aires. Argentina.

Correa, M. N. (1984a). Flora Patagónica. Tomo VIII. Parte IV a. Dicotyledones Dialipétalas (Salicaceae a Cruciferae). Colección Científica de INTA. Buenos Aires. Argentina.

Correa, M. N. (1984b). Flora Patagónica. Tomo VIII. Parte IV b. Dicotyledones Dialipétalas (Droseraceae a Leguminosae). Colección Científica de INTA. Buenos Aires. Argentina.

Correa, M. N. (1988a). Flora Patagónica. Tomo VIII. Parte I. Colección Científica de INTA.
Buenos Aires. Argentina.

Correa, M. N. (1988b). Flora Patagónica. Tomo VIII. Parte V. Dicotyledones Dialipétalas (Oxalidaceaea Cornaceae). Colección Científica de INTA. Buenos Aires. Argentina.

Correa, M. N. (1999). Flora Patagónica. Tomo VIII. Parte VI Flora Dicotyledones Gamopétalas (Ericaceae a Calyceraceae). Colección Científica de INTA. Buenos Aires. Argentina.

Donoso, C. (1993). Bosques templados de Chile y Argentina. Variación, estructura y dinámica. Ecología Forestal. Santiago: Editorial Universitaria.

Donoso, C., Steinke, L., \& Premoli, A. (2006). Nothofagus antarctica (G. Forster) Oerst. Las especies arbóreas de los bosques templados de Chile y Argentina. Autoecología. Valdivia, Chile. Marisa Cuneo Ediciones, 401-410.

Ezcurra, C., \& Brion, C. (2005). Plantas del Nahuel Huapi: Catálogo de la Flora Vascular del Parque Nacional Nahuel Huapi, Argentina. San Carlos de Bariloche: Universidad Nacional del Comahue y Red Latinoamericana de Botánica.

Fischer, A. G. (1960). Latitudinal variations in organic diversity. Evolution, 14(1), 64-81.

García, D. (2011). Efectos biológicos de la fragmentación de hábitats: nuevas aproximaciones para resolver un viejo problema. Ecosistemas, 20(2-3), 1-10.

Gotelli, N. J., \& Colwell, R. K. (2001). Quantifying biodiversity: procedures and pitfalls in the measurement and comparison of species richness. Ecology letters, 4(4), 379-391.

Greslebin, A., Vélez, M. L., \& Garbelotto, M. (2015). Austrocedrus forests of South America are pivotal ecosystems at risk due to the emergence of an exotic tree disease: can a joint effort of research and policy save them?

Haila, Y. (1995). Natural dynamics as a model for management: is the analogue practicable. Northern wilderness areas: ecology, sustainability, values. Arctic Centre Publications, 7, 9-26.

Halffter, G. (1998). A strategy for measuring 
landscape biodiversity. Biology International (France).

Halffter, G. \& Moreno, C.E. (2005). Significado biológico de la diversidad alfa, beta y gamma. En G. Halffter, J. Soberón, P. Koleff y A. Melic (Eds.), Sobre diversidad biológica: el significado de las diversidades alfa, beta y gamma. Cuadernos de biodiversidad. España, 4, 5-18.

Harrison, S., Ross, S., \& Lawton, J. (1992). Beta Diversity on Geographic Gradients in Britain. Journal of Animal Ecology, 61(1), 151-158.

Hijmans, R. J., Cameron, S. E., Parra, J. L., Jones, P.G ., \& Jarvis, A. (2005). Very high resolution interpolated climate surfaces for global land areas. International Journal of Climatology, 25, 1965-1978.

Hill, M. O. (1973). Diversity and evenness: a unifying notation and its consequences. Ecology, 54(2), 427-432.

Honnay, O., Hermy, M., \& Coppin, P. (1999). Effects of area, age and diversity of forest patches in Belgium on plant species richness, and implications for conservation and reforestation. Biological conservation, 87(1), 73-84.

Jiménez-Valverde, A., \& Hortal, J. (2000). Las curvas de acumulación de especies y la necesidad de evaluar los inventarios biológicos. Revista Ibérica de Aracnología, 8, 151-161.

Koleff, P., Gaston, K. J., \& Lennon, J. J. (2003). Measuring beta diversity for presenceabsence data. Journal of Animal Ecology, 72(3), 367-382.

Legendre, P. (2014). Interpreting the replacement and richness difference components of beta diversity. Global Ecology and Biogeography, 23(11), 1324-1334.

Legendre, P., Borcard, D., \& Peres-Neto, P. R. (2005). Analyzing beta diversity: partitioning the spatial variation of community composition data. Ecological Monographs, 75(4), 435-450.

Lennon, J. J., Koleff, P., Greenwood, J. J. D., \& Gaston, K. J. (2001). The geographical structure of British bird distributions: diversity, spatial turnover and scale. Journal of Animal Ecology, 70(6), 966-979.

Magnago, L. F. S., Edwards, D. P., Edwards, F. A., Magrach, A., Martins, S. V., \& Laurance, W. F. (2014). Functional attributes change but functional richness is unchanged after fragmentation of Brazilian Atlantic forests. Journal of Ecology, 102(2), 475-485.

Magurran, A. E. (1988). Why diversity? In Ecological diversity and its measurement (pp. 1-5). Springer, Dordrecht.

Montgomery, D. C. (1991). Control Estadístico de la Calidad Grupo Editorial Iberoamérica. ISBN 9687270799.

Moreno, C. E. (2001). Manual de métodos para medir la biodiversidad (No. Sirsi) i9789688345436). Universidad Veracruzana.

Mueller-Dombois, D. \& H. Ellenberg. (1974). Aims and methods of vegetation ecology. John Wiley \& Sons. New York. 547 pp.

Myklestad, A., \& Sæetersdal, M. (2004). The importance of traditional meadow management techniques for conservation of vascular plant species richness in Norway. Biological conservation, 118(2), 133-139.

Nekola, J. C., \& White, P. S. (1999). The distance decay of similarity in biogeography and ecology. Journal of Biogeography, 26(4), 867-878.

Olsen, S. R. (1954). Estimation of available phosphorus in soils by extraction with sodium bicarbonate. United States Department of Agriculture; Washington.

Peri, P. L., Martínez Pastur, G., Monelos, L., \& Beroiz, M. (2013). La distribución continental más oriental de Nothofagus antarctica en el río Gallegos (Santa Cruz). Anales del Instituto de la Patagonia, 41(1), 113-117.

Peri, P. P., \& Ormaechea, S. (2013). Relevamiento de los bosques nativos de ñire (Nothofagus antarctica) en Santa Cruz: base para su conservación y manejo.

Pianka, E. R. (1966). Latitudinal gradients in species diversity: a review of concepts. The American Naturalist, 100(910), 33-46.

Premoli, A. C., Souto, C. P., Rovere, A. E., Allnut, T. R., \& Newton, A. C. (2002). Patterns of isozyme variation as indicators of biogeographic history in Pilgerodendron 
uviferum (D. Don) Florin. Diversity and Distributions, 8(2), 57-66.

Pütz, S., Groeneveld, J., Alves, L. F., Metzger, J. P., \& Huth, A. (2011). Fragmentation drives tropical forest fragments to early successional states: a modelling study for Brazilian Atlantic forests. Ecological Modelling, 222(12), 1986-1997.

Rahman, M. M., \& Govindarajulu, Z. (1997). A modification of the test of Shapiro and Wilk for normality. Journal of Applied Statistics, 24(2), 219-236.

Rasband, W. S. (2011). US National Institutes of Health. Bethesda, Maryland, EE. UU. http:// imagej. nih. gov/ij.

Rodríguez, P., Soberón, J., \& Arita, H. T. (2003). El componente beta de la diversidad de mamíferos de México. Acta zoológica mexicana, (89), 241-259.

Schmithüsen, J. (1956). Die raunmliche Ordnung der chilenischen Vegetation. Bonner Geographische Abhandlungen. 17, 1-86.

Scott, J. M., Norse, E. A., Arita, H., Dobson, A., Estes, J. A., Foster, M., \& Soulé, M. E. (1999). The issue of scale in selecting and designing biological reserves. Continental Conservation, scientific foundations of regional reserve networks. Washington, DC: Island Press.

Stehli, F. G., Douglas, R. G., \& Newell, N. D. (1969). Generation and maintenance of gradients in taxonomic diversity. Science, 164(3882), 947-949.

Stevens, G. C. (1989). The latitudinal gradient in geographical range: how so many species coexist in the tropics. The American Naturalist, 133(2), 240-256.

Suárez, M. L., Ghermandi, L., \& Kitzberger, T. (2004). Factors predisposing episodic droughtinduced tree mortality in Nothofagus-site, climatic sensitivity and growth trends. Journal of Ecology, 92(6), 954-966.

ter Braak, C. J. F. (1995). Ordination. In Data analysis in community and landscape ecology. Cambridge University Press. (91274).

ter Braak, C. J. F. (2002). P. milauer, 2002. CANOCO reference manual and CanoDraw for Windows user's guide: software for canonical community ordination (version 4.5), Microcomputer Power, Ithaca, USA.

van der Hammen, T., \& Cleef, A. (1983). Datos para la historia de la flora andina. Revista Chilena de Historia Natural, 56(2), 97107.

Villagrán, C. (1995). El cuaternario en Chile: evidencias de cambio climático. Cambios cuaternarios en América del Sur. En: J. Argollo \& Ph. Mourguiart (Eds). 191-214.

Villagrán, C., \& Hinojosa, L. F. (1997). Historia de los bosques del sur de Sudamérica, II: Análisis fitogeográfico. Revista Chilena de Historia Natural, 70(2), 1-267.

Villagrán, C., \& Armesto, J. J. (2005). Fitogeografía histórica de la Cordillera de la Costa de Chile. Historia, biodiversidad y ecología de los bosques costeros de Chile, 708, 99115.

Villagrán, C., Hinojosa, L. F., Llorente-Bousquets, J., \& Morrone, J. J. (2005). Esquema biogeográfico de Chile. Regionalización Biogeográfica en Iberoamérica y Tópicos Afines. Primeras Jornadas Biogeográficas de la Red Iberoamericana de Biogeografía y Entomología Sistemática (pp. 551-557). Mexico City: Las Prensas de Ciencias, UNAM. Wilcove, D. S., \& May, R. M. (1986). National park boundaries and ecological realities. Nature, 324(6094), 206.

Whittaker, R. H. (1972). Evolution and measurement of species diversity. Taxon, 213-251.

Wright, D. H., \& Reeves, J. H. (1992). On the meaning and measurement of nestedness of species assemblages. Oecologia, 92(3), 416-428.

Wright, D. H., Patterson, B. D., Mikkelson, G. M., Cutler, A., \& Atmar, W. (1997). A comparative analysis of nested subset patterns of species composition. Oecologia, 113(1), 1-20.

Zuloaga, F. (2018). Flora del Conosur. Catálogo de las Plantas Vasculares. http://www2. darwin.edu.ar/Proyectos/FloraArgentina/ Especies.asp. Consultado el 18 de octubre de 2018. 


\section{ANEXO I}

Listado de las especies identificadas. Status: detalle del origen. Hábito: detalle del tipo de vida. Exclusividad: indica si la especie es exclusiva del ambiente relicto (R) o bosque continuo aledaño (A).

\section{Apiaceae}

Familias / Especies

Azorella ameghinoi

Azorella fuegiana

Azorella lycopodioides

Azorella monantha

Azorella prolifera

Azorella trifoliolata

Azorella trifurcata

Bolax gummifera

Huanaca andina

Huanaca burkartii

Osmorhiza chilensis

\section{Asteraceae}

Agoseris coronopifolia

Antennaria chilensis

Baccharis magellanica

Chiliotrichum diffusum

Erigeron leptopetalus

Erigeron myosotis

Gamochaeta nivalis

Gamochaeta spiciformis

Haplopoppus sp.

Hieracium patagonicum

Hieracium praealtum

Hypochaeris arenaria

Hypochaeris incana

Hypochaeris sp.

Leptinella scariosa

Leucanthemum vulgare

Leucheria achillaeifolia

Leucheria hahnii

Leucheria purpurea

$\begin{array}{ll}\text { Endémica } & \text { Hierba Perenne } \\ \text { Endémica } & \text { Hierba Perenne } \\ \text { Endémica } & \text { Hierba o Subarbusto Perenne } \\ \text { Endémica } & \text { Hierba o Subarbusto Perenne } \\ \text { Endémica } & \text { Arbusto Perenne } \\ \text { Endémica } & \text { Hierba o Subarbusto Perenne } \\ \text { Endémica } & \text { Hierba o Subarbusto Perenne } \\ \text { Endémica } & \text { Hierba o Subarbusto Perenne } \\ \text { Indefinido } & \text { Hierba Perenne } \\ \text { Endémica } & \text { Hierba Perenne } \\ \text { Nativa } & \text { Hierba Perenne }\end{array}$

$\mathrm{R}$

A

A

$\begin{array}{ll}\text { Endémica } & \text { Hierba Perenne } \\ \text { Endémica } & \text { Hierba Perenne } \\ \text { Endémica } & \text { Arbusto Perenne } \\ \text { Endémica } & \text { Subarbusto Perenne } \\ \text { Endémica } & \text { Subarbusto Perenne } \\ \text { Endémica } & \text { Hierba Perenne } \\ \text { Endémica } & \text { Hierba Perenne } \\ \text { Endémica } & \text { Hierba Perenne } \\ \text { Indefinido } & \text { Indefinido } \\ \text { Endémica } & \text { Hierba Perenne } \\ \text { Adventicia } & \text { Hierba Perenne } \\ \text { Nativa } & \text { Hierba Perenne } \\ \text { Endémica } & \text { Hierba Perenne } \\ \text { Indefinido } & \text { Hierba } \\ \text { Endémica } & \text { Hierba Perenne } \\ \text { Adventicia } & \text { Hierba Perenne } \\ \text { Endémica } & \text { Hierba Perenne } \\ \text { Endémica } & \text { Hierba Perenne } \\ \text { Endémica } & \text { Hierba Perenne } \\ & \end{array}$

$\mathrm{R}$

A

A 


\begin{tabular}{|c|c|c|c|}
\hline Familias / Especies & Status & Hábito & Exclusividad \\
\hline Nardophyllum bryoides & Endémica & Arbusto Perenne & \\
\hline Nassauvia aculeata & Endémica & Hierba o Arbusto Perenne & \\
\hline Nassauvia sprengelioides & Nativa & Hierba Perenne & A \\
\hline Perezia magellanica & Endémica & Hierba Perenne & $\mathrm{R}$ \\
\hline Perezia pilifera & Endémica & Hierba Perenne & \\
\hline Perezia recurvata & Endémica & Hierba Perenne & \\
\hline Senecio filaginoides & Endémica & Arbusto Perenne & \\
\hline Senecio magellanicus & Endémica & Hierba Perenne & \\
\hline Senecio martinensis & Endémica & Hierba Perenne & A \\
\hline Senecio pachyphyllos & Endémica & Subarbusto Perenne & A \\
\hline Senecio patagonicus & Endémica & Subarbusto Perenne & \\
\hline Senecio sp. & Endémica & Subarbusto Perenne & \\
\hline Senecio tricuspidatus & Endémica & Arbusto Perenne & \\
\hline Taraxacum officinale & Adventicia & Hierba Perenne & \\
\hline \multicolumn{4}{|l|}{ Berberidaceae } \\
\hline Berberis empetrifolia & Endémica & Subarbusto Perenne & \\
\hline Berberis microphylla & Endémica & Arbusto Perenne & \\
\hline \multicolumn{4}{|l|}{ Blechnaceae } \\
\hline Austroblechnum penna-marina & Cosmopolita & Hierba Perenne & $\mathrm{R}$ \\
\hline \multicolumn{4}{|l|}{ Boraginaceae } \\
\hline Myosotis stricta & Adventicia & Hierba & \\
\hline Phacelia secunda & Nativa & Hierba o Subarbusto Perenne & \\
\hline \multicolumn{4}{|l|}{ Brassicaceae } \\
\hline Capsella bursa-pastoris & Adventicia & Hierba Anual o Bianual & \\
\hline Cardamine glacialis & Endémica & Hierba Perenne & \\
\hline Draba magellanica & Endémica & Hierba Perenne & \\
\hline Draba verna & Endémica & Subarbusto Perenne & A \\
\hline Noccaea magellanica & Endémica & Hierba Perenne & \\
\hline Raphanus raphanistrum & Adventicia & Hierba Anual o Bianual & $\mathrm{R}$ \\
\hline \multicolumn{4}{|l|}{ Calceolariaceae } \\
\hline Calceolaria biflora & Endémica & Hierba Perenne & \\
\hline Calceolaria polyrrhiza & Endémica & Hierba Perenne & \\
\hline Calceolaria uniflora & Endémica & Hierba Perenne & \\
\hline \multicolumn{4}{|l|}{ Campanulaceae } \\
\hline Lobelia oligophylla & Nativa & Hierba Perenne & $\mathrm{R}$ \\
\hline
\end{tabular}


Familias / Especies

Status

Hábito

Exclusividad

Caryophyllaceae

Carex sp.

Indefinido

Hierba

$\mathrm{R}$

Caryophillacea sp. 1

Indefinido

Hierba

Caryophillacea sp. 2

Cerastium arvense

Indefinido

Hierba

A

Adventicia Hierba Perenne

Colobanthus subulatus

Endémica

Hierba Perenne

Silene antarctica

Endémica

Hierba Perenne

Silene chilensis

Endémica

Hierba Perenne

Silene magellanica

Endémica

Hierba Perenne

$\mathrm{R}$

Stellaria media

Adventicia

Hierba Anual

Corsiaceae

Arachnitis uniflora

Endémica

Hierba Perenne

$\mathrm{R}$

\section{Cyperaceae}

Carex fuscula

Endémica

Hierba Perenne

Carex gayana

Nativa

Hierba Perenne

Schoenoplectus americanus

Nativa

Hierba Perenne

\section{Empetraceae}

Empetrum rubrum

Nativa

Subarbusto Perenne

\section{Ericaceae}

Gaultheria mucronata

Endémica

Arbusto Perenne

A

Gaultheria pumila

Endémica

Arbusto Perenne

\section{Escalloniaceae}

Escallonia rubra

Endémica

Arbusto Perenne

A

Fabaceae

Adesmia boronioides

Endémica

Arbusto Perenne

Adesmia corymbosa

Endémica

Hierba Perenne

A

Adesmia lotoides

Endémica

Hierba Perenne

Adesmia pumila

Endémica

Hierba Perenne

Adesmia salicornioides

Endémica

Subarbusto Perenne

Astragalus nivicola

Endémica

Hierba Perenne

A

Nativa

Hierba o Enredadera Perenne

Adventicia

Hierba Anual

$\mathrm{R}$

Trifolium dubium

Adventicia

Hierba Perenne

Vicia bijuga

Endémica

Hierba Anual o Bianual

\section{Gentianaceae}

Gentiana prostrata

Nativa

Hierba Anual 


\begin{tabular}{|c|c|c|c|}
\hline Familias / Especies & Status & Hábito & Exclusividad \\
\hline $\begin{array}{l}\text { Gentianella magellanica } \\
\text { Geraniaceae }\end{array}$ & Endémica & Hierba Anual & \\
\hline Geranium magellanicum & Endémica & Hierba Perenne & \\
\hline Geranium sessiliflorum & Nativa & Hierba Perenne & $\mathrm{R}$ \\
\hline \multicolumn{4}{|l|}{ Grossulariaceae } \\
\hline Ribes cucullatum & Endémica & Arbusto Perenne & \\
\hline Ribes magellanicum & Endémica & Arbusto Perenne & \\
\hline \multicolumn{4}{|l|}{ Gunneraceae } \\
\hline Gunnera magellanica & Nativa & Hierba Perenne & \\
\hline \multicolumn{4}{|l|}{ Indefinido } \\
\hline Indefinido sp. 1 & Indefinido & Hierba & $\mathrm{R}$ \\
\hline Indefinido sp. 2 & Indefinido & Hierba & A \\
\hline \multicolumn{4}{|l|}{ Iridaceae } \\
\hline Olsynium junceum & Nativa & Hierba Perenne & \\
\hline Sisyrinchium arenarium & Endémica & Hierba Perenne & $\mathrm{R}$ \\
\hline $\begin{array}{l}\text { Solenomelus segethii } \\
\text { Juncaceae }\end{array}$ & \multicolumn{2}{|c|}{ Juncaceae } & \\
\hline Luzula racemosa & Nativa & Hierba Perenne & \\
\hline $\begin{array}{l}\text { Marsippospermum reichei } \\
\text { Lamiaceae }\end{array}$ & Endémica & Hierba Perenne & \\
\hline $\begin{array}{l}\text { Clinopodium darwinii } \\
\text { Lycopodiaceae }\end{array}$ & Endémica & Hierba o Subarbusto Perenne & A \\
\hline $\begin{array}{l}\text { Austrolycopodium magellanicum } \\
\text { Nanodaceae }\end{array}$ & Nativa & Hierba Perenne & A \\
\hline Nanodea muscosa & Endémica & Hierba Perenne & \\
\hline \multicolumn{4}{|l|}{ Nothofagaceae } \\
\hline Nothofagus pumilio & Endémica & Árbol Perenne & A \\
\hline \multicolumn{4}{|l|}{ Orobanchaceae } \\
\hline Euphrasia antarctica & Endémica & Hierba Anual & \\
\hline \multicolumn{4}{|l|}{ Oxalidaceae } \\
\hline Oxalis enneaphylla & Endémica & Hierba Perenne & \\
\hline Oxalis laciniata & Endémica & Hierba & \\
\hline \multicolumn{4}{|l|}{ Plantaginaceae } \\
\hline Ourisia breviflora & Endémica & Hierba Perenne & $\mathrm{R}$ \\
\hline Plantago uniglumis & Endémica & Hierba Perenne & \\
\hline Veronica serpyllifolia & Adventicia & Hierba Perenne & \\
\hline
\end{tabular}


Familias / Especies

\section{Plumbaginaceae}

Armeria maritima

\section{Poaceae}

Agrostis capillaris

Avebella flexuosa

Bromus catharticus

Elymus patagonicus

Festuca arundinacea

Festuca australis

Festuca magellanica

Festuca pallescens

Holcus lanatus

Hordeum comosum

Phleum alpinum

Poa alopecurus

Poa pratensis

Poa spiciformis

Trisetum spicatum

\section{Polemoniaceae}

Microsteris gracilis

\section{Polygalaceae}

Polygala salasiana

Rumex acetosella

\section{Ranunculaceae}

Anemone multifida

Caltha sagittata

Halerpestes uniflora

Ranunculus muricatus

Ranunculus peduncularis

\section{Rosaceae}

Acaena magellanica

Acaena ovalifolia

Acaena pinnatifida

Geum magellanicum

Rubus geoides
Endémica Hierba Perenne

Naturalizada Hierba Perenne

Nativa

Hierba Perenne

Endémica

Hierba

Endémica

Hierba Perenne

$\mathrm{R}$

Introducida

Hierba Perenne

Endémica

Hierba Anual

$\mathrm{R}$

Endémica Hierba Perenne

Endémica Hierba Perenne

Adventicia

Hierba Anual

A

Nativa

Hierba Perenne

Nativa

Hierba Perenne

Endémica

Hierba Perenne

Adventicia

Hierba Perenne

A

Endémica

Hierba Perenne

Nativa

Hierba Perenne

$\mathrm{R}$

Nativa Hierba Anual

Endémica Hierba Perenne

A

Adventicia Hierba Perenne

Nativa

Hierba Perenne

Nativa

Hierba Perenne

Nativa

Hierba Perenne

Adventicia

Hierba Anual

$\mathrm{R}$

Endémica

Hierba Perenne

A

Nativa

Hierba Perenne

Endémica

Hierba Perenne

Endémica

Hierba Perenne

Endémica

Hierba Perenne

Endémica

Hierba Perenne
A 
Familias / Especies

\section{Rubiaceae}

Galium antarcticum

Galium aparine

Galium fuegianum

Galium richardianum

Oreopolus glacialis

Saxifragaceae

Saxifraga magellanica

Schoepfiaceae

Arjona longifolia

Arjona patagonica

Arjona pusilla

Urticaceae

Urtica dioica

Valerianaceae

Valeriana carnosa

Violaceae

Viola maculata

Viola magellanica
Status

Hábito

Exclusividad

Endémica

Hierba Anual

A

Adventicia

Hierba Anual

Endémica

Hierba Anual

Endémica

Hierba Anual

Endémica

Hierba Anual

A

A

Nativa

Hierba Perenne

A

Endémica

Hierba Perenne

A

Endémica

Hierba Perenne

Endémica

Hierba Perenne

Adventicia Hierba o Arbusto Perenne

$\mathrm{R}$

Endémica

Hierba Perenne

Endémica

Hierba Perenne

Endémica

Hierba Perenne 